\title{
Analysis of a possible association between oral lichen planus and drug intake. A controlled study
}

\author{
Silvio-K. Hirota ${ }^{1}$, Ricardo-A. Moreno ${ }^{2}$, Carlos-H. R. dos Santos ${ }^{2}$, Juliana Seo ${ }^{1}$, Dante-A. Migliari ${ }^{1}$ \\ ${ }^{1}$ DDS,PhD, DDS, DDS,PhD, Department of Oral Diagnosis, School of Dentistry, University of São Paulo, Brazil \\ ${ }^{2} \mathrm{MD}, \mathrm{PhD}, \mathrm{MD}, \mathrm{PhD}$ Department of Psychiatry, School of Medicine, University of São Paulo, Brazil
}

Correspondence:

Universidade de São Paulo,

Faculdade de Odontologia,

Departamento de Estomatologia,

Disciplina de Estomatologia Clínica,

Av. Prof. Lineu Prestes, 2227, Cidade Universitária,

São Paulo, SP-Brazil 05508-000

damiglia@usp.br

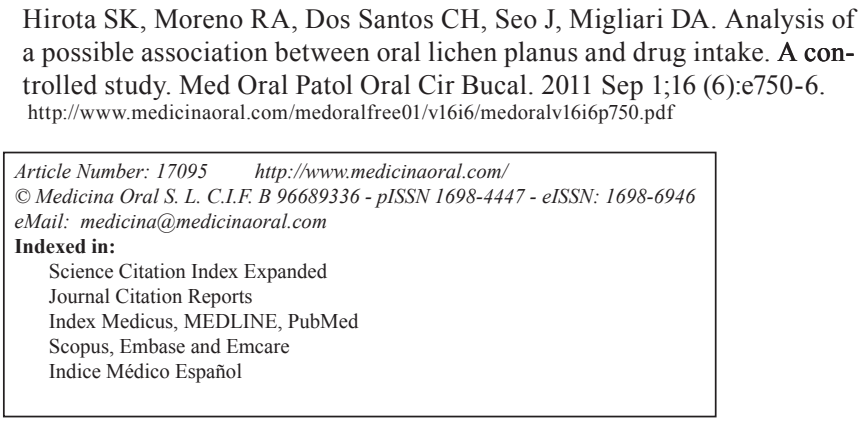
trolled study. Med Oral Patol Oral Cir Bucal. 2011 Sep 1;16 (6):e750-6.

Index Medicus, MEDLINE, PubMed

Scopus, Embase and Emcare

\begin{abstract}
Objectives: To investigate whether daily systemic and/or topical medication contributes to the development of oral lichen planus (OLP) lesions.

Study Design: The study involved 110 OLP patients and 76 control subjects, matched by age, race and sex. The analyzed data included medical records, drug intake and topical medication. Criteria for analysis of drug intake included: (1) ATC-code drug classification; (2) number of different drugs used daily in the categories of monopharmacy (1 drug), minor polypharmacy (2-4 drugs), and major polypharmacy ( $>5$ drugs); and (3) drugs implicated in lichenoid reactions (DILRs).

Results: Sixty (54.5\%) of the 110 OLP patients reported daily medication (prior to the appearance of the OLP lesion) compared to $52(68.4 \%)$ of the 76 control subjects. No statistical difference was found between the two groups in terms of systemic diseases, number of medicated individuals in the categories of mono- and polypharmacy, nor use of DILRs ( $\mathrm{P}>0.05)$. Regarding the clinical forms and site of involvement, a statistically significant difference was only found for the clinical erosive form of OLP, seen more frequently in non-DILR $(P=0.04)$ and nonmedicated OLP patients $(\mathrm{P}=0.02)$ than in DILR OLP patients. Daily use of topical oral medication was reported by $2(1.8 \%)$ OLP patients and $1(1.3 \%)$ control subject.

Conclusions: It seems that the use of systemic medication does not lead to a significant increase in the incidence of OLP lesions. For their part, lichenoid drug reactions are likely to occur only in a very low percentage of patients.
\end{abstract}

Key words: Oral lichen planus, oral lichenoid drug reactions, oral manifestations, drug intake. 


\section{Introduction}

Lichen planus (LP) is an inflammatory mucocutaneous disease of unknown etiology, and thought to arise as a result of an immune response -mainly by CD8+ lymphocytes - to antigens on lesional keratinocytes $(1,2)$. Oral lichen planus (OLP) affects from 0.1 to about $4 \%$ of individuals, occurring mostly in middle-aged adults, with a female predominance at a ratio of approximately 2:1 $(3,4)$.

Several studies have suggested a possible relationship between OLP and daily intake of medicine $(3,5-7)$. OLP lesions presumed to be related to long-term drug intake are referred to as lichenoid drug reactions (LDR). The diagnosis of LDR usually relies on subjective criteria since the clinical and histopathological features of LDR lesions are identical or similar to those of idiopathic OLP lesions. Additionally, it is very difficult to identify the drug associated to LDR based on the patient's medical history. The best criterion for diagnosing LDR is based on the observation that the lesion remits with drug withdrawal and returns on re-challenge, but this is almost always impractical because of the need for patient safety (6-9).

Many types of drugs have been implicated as a causative factor for LDR, especially the non-steroidal antiinflammatory drugs. In one study involving 75 patients with OLP, of whom 20 were taking nonsteroidal antiinflammatory drug, 7 had a complete resolution of their oral lesions after withdrawal of the drug. Of these 7 patients, 2 produced a recurrence when later rechallenged with the offending drug (9).

There have been few articles comparing the profile of drug intake by OLP patients with that of a control group $(4,10)$. The purpose of the present study was to investigate whether the daily systemic and/or topical medicine used by patients with OLP contributes to the development of their oral lesions. A control group matched by age, race and sex without oral lesions was included for comparison of medication intake.

\section{Material and Methods}

The study group comprised 110 patients (87 female, $79.1 \%$; 23 male, $20.9 \%$, ratio $\mathrm{f} / \mathrm{m}=3.8: 1$ ) with OLP referred to the clinic of Oral Diagnosis, School of Dentistry at the University of São Paulo, during the period from May 2005 to July 2009. The mean age of patients with LPO was 53.6 years (range 27-95 years); 80 were white $(72.7 \%)$ and 30 nonwhite $(27.2 \%)$. The control group was composed of 76 patients (59 female, $77.6 \%$; 17 male, 22.4\%) without oral and/or cutaneous lichen planus or autoimmune diseases. The selection of the control group was made among individuals who came to our clinic seeking dental treatment. The mean age of this group was 53.7 years (range 26-82 years); 50 were white $(65.8 \%)$ and 26 nonwhite $(34.2 \%)$. OLP patients suspected as having extra-oral lesions of LP were referred to a Dermatologic unit at the School of Medicine, University of São Paulo, for further evaluation. This study was approved by the Committee on Ethics of the University of São Paulo.

Patients with OLP were evaluated in the initial consultation through application of a clinical protocol. The diagnosis of OLP was made according to the criteria described by Kramer et al. (11), i.e., clinically, by the presence of white papules and/or striae usually with bilateral involvement, and histopatholgically, by signs of "liquefaction degeneration" in the basal cell layer (degenerative changes to the basal cells) along with the presence a well-defined band-like zone of inflammatory infiltrate confined to the superficial part of the connective tissue, this infiltrate being composed almost exclusively by lymphocytes, and absence of epithelial dysplasia. Patients suspected as having oral lichenoid contact reaction to amalgam fillings were not included. Clinical characteristics of the OLP lesions were analyzed, including the clinical forms, site, duration, and presence of symptomatology. The clinical forms were categorized into reticular, atrophic, erosive and plaque. The reticular form was characterized by the presence of white striae and/or papules exhibiting a lace-like and/ or irradiated pattern; the atrophic form by an erythematous lesion associated with reticular features; the erosive form by a combination of ulceration and features of the atrophic form; and the plaque-like by a raised, flat white lesion with a smooth or rough surface with the presence of reticular features either at the periphery of the plaque or elsewhere in the oral mucosa. Prior to biopsy all OLP patients were tested for the presence of Candida spp. by PAS (periodic acid-Schiff), and only those patients who tested positive were treated with antifungal agent (topical Nystatin oral suspension, used as mouthwash) for 2 weeks before biopsy.

Data collected for analysis of both groups included age, sex, race, medical records, systemic disease, drug intake and topical medication such as mouthwashes. Criteria for analysis of drug intake in both groups included: (1) drug classification according to the ATC code (12); (2) the number of different drugs used daily in the categories of monopharmacy (1 drug), minor polypharmacy (2-4 drugs), and major polypharmacy ( $>5$ drugs); and (3) drugs reported to have the potential to induce oral and/or cutaneous LDR, according to Scully and Bagan (8). Data were analyzed by unconditional logistic regression. Associations between lichen planus and covariates were assessed by odds ratio (OR) point with a 95\% confidence interval. Fisher's exact test was used when the observed frequencies were less than 5. The statistical significance level was set for $\mathrm{P} \leq 0.05$. 


\section{Results}

Of the 110 OLP patients, 60 (54.5\%) had been using daily medication since prior to the appearance of the OLP lesion (termed as medicated OLP patients), 22 (20\%) were presently using daily medication, but had began using it only after the appearance of the OLP lesion, while 28 $(25.5 \%)$ did not report daily use of medication. These 2 latter categories of patients were considered as nonmedicated OLP patients, since in both cases there was no possibility for drugs to have played a part in the onset of their OLP lesions. For the control group, daily use of medication was reported by $52(68.4 \%)$ of the 76 subjects. The clinical profiles of the OLP group and control group are shown in (Table 1), there being no significant statistical difference between the two groups in terms of sex, race, systemic diseases or consumption of tobacco or alcohol $(P>0.05)$. Extra-oral lesions of LP were found in 11 OLP patients $(10 \%)$. Of these, 1 had cutaneous and genital lesions, 8 had only cutaneous lesions, while 2 had only genital lesions. The dermatologic diagnosis of the extraoral lesions was made on a clinical basis supported by the oral and histopathologic data of the OLP lesions, with no additional biopsy being taken. The PAS-test for Candida was positive in 19 cases $(17.3 \%)$. In these patients, most of the lesions were of reticular or atrophic form, 3 cases were of erosive form. Thirteen were symptomatic while 6 were symptomless. After antifungal treatment patients reported subjective improvement of their symptoms, but the clinically observed appearance of their lesions remained unchanged.

Table 1. Clinical profile of the OLP patients and control subjects.

\begin{tabular}{|c|c|c|c|c|c|c|}
\hline & \multicolumn{6}{|c|}{ Patients } \\
\hline & \multicolumn{3}{|c|}{ LPO Group $(n=110)$} & \multicolumn{3}{|c|}{ Control Group $(n=76)$} \\
\hline & Male (\%) & Female (\%) & Total (\%) & Male (\%) & Female $(\%)$ & Total (\%) \\
\hline Number & $23(20.9)$ & $87(79.1)$ & $110(100)$ & $17(22.4)$ & $59(77.6)$ & $76(100)$ \\
\hline Mean age (range) yr & $52.2(36-72)$ & $54(27-95)$ & $53.6(27-95)$ & $57.7(44-76)$ & $52.4(26-82)$ & $53.7(26-82)$ \\
\hline \multicolumn{7}{|l|}{ Race } \\
\hline White & $15(65.2)$ & $65(74.7)$ & $80(72.7)$ & $11(61.1)$ & $39(67.2)$ & $50(65.8)$ \\
\hline Non-white & $8(34.8)$ & $22(25.3)$ & $30(27.3)$ & $6(33.3)$ & $20(34.5)$ & $26(34.2)$ \\
\hline \multicolumn{7}{|l|}{ History of disease } \\
\hline Hypertension & $6(26.1)$ & $26(29.9)$ & $32(29.1)$ & $6(33.3)$ & $20(34.5)$ & $26(34.2)$ \\
\hline Diabetes & $6(26.1)$ & $12(13.8)$ & $18(16.4)$ & $3(16.7)$ & $6(10.3)$ & $9(11.8)$ \\
\hline Hypotireoidism & - & $12(13.8)$ & $12(10.9)$ & - & $4(6.9)$ & $4(5.3)$ \\
\hline Hepatitis B & $2(8.7)$ & $3(3.5)$ & $5(4.5)$ & - & $2(3.4)$ & $2(2.6)$ \\
\hline Hepatitis C & - & $2(2.3)$ & $2(1.8)$ & - & $2(3.4)$ & $2(2.6)$ \\
\hline Anemia history & $1(4.3)$ & $13(14.9)$ & $14(12.7)$ & $2(11.1)$ & $7(12.1)$ & $9(11.8)$ \\
\hline Allergy & $1(4.3)$ & $17(19.5)$ & $18(16.4)$ & $1(5.9)$ & $10(17.2)$ & $11(14.5)$ \\
\hline \multicolumn{7}{|l|}{ Habits } \\
\hline Present smokers & $1(4.3)$ & $10(11.5)$ & $11(10)$ & $2(11.1)$ & $12(20.7)$ & $14(18.4)$ \\
\hline Ex-smokers $(>2$ years $)$ & $14(60.9)$ & $23(26.4)$ & $37(33.6)$ & $8(44.4)$ & $12(20.7)$ & $20(26.3)$ \\
\hline Present drinker & $11(47.8)$ & $13(14.9)$ & $24(21.8)$ & $10(55.6)$ & $14(24.1)$ & $25(32.9)$ \\
\hline Ex-drinker $(>2$ years $)$ & $5(21.8)$ & $3(3.5)$ & $8(7.3)$ & $2(11.1)$ & $2(3.4)$ & $4(5.3)$ \\
\hline
\end{tabular}

$\mathrm{n}=$ number of patients. 
Table 2. Drugs most used by OLP patients and control subjects.

\begin{tabular}{|c|c|c|c|}
\hline Medicated OLP patients $(n=60)$ & $\mathbf{N}(\%)$ & Medicated control subjects $(n=52)$ & $\mathbf{N}(\%)$ \\
\hline \multirow[t]{2}{*}{ Antihypertensives } & $25(41.7)$ & Antihypertensives $\dagger$ & $29(55.8)$ \\
\hline & & $\begin{array}{l}\text { C02A Antiadrenergic agents, centrally } \\
\text { acting }\end{array}$ & $1(1.9)$ \\
\hline C03A Low-ceiling diuretics, thiazides & $8(13.3)$ & C03A Low-ceiling diuretics, thiazides & $11(21.1)$ \\
\hline \multirow[t]{2}{*}{$\begin{array}{l}\text { C03B Low-ceiling diuretics, excluding } \\
\text { thiazides }\end{array}$} & $4(6.7)$ & $\begin{array}{l}\text { C03B Low-ceiling diuretics, excluding } \\
\text { thiazides }\end{array}$ & $2(3.8)$ \\
\hline & & C03C High-ceiling diuretics & $1(1.9)$ \\
\hline C03D Potassium-sparing agents & $1(1.7)$ & & \\
\hline $\begin{array}{l}\text { C03E Diuretics and potassium-sparing } \\
\text { agents in combination }\end{array}$ & $1(1.7)$ & $\begin{array}{l}\text { C03E Diuretics and potassium-sparing } \\
\text { agents in combination }\end{array}$ & $2(3.8)$ \\
\hline \multirow[t]{2}{*}{ C07A Beta blocking agents } & $5(8.3)$ & C07A Beta blocking agents & $7(13.5)$ \\
\hline & & $\begin{array}{l}\text { C07C Beta blocking agents and other } \\
\text { diuretics (não-tiazídicos) }\end{array}$ & $1(1.9)$ \\
\hline $\begin{array}{l}\text { C08C Selective calcium channel blockers } \\
\text { with mainly vascular effects }\end{array}$ & $2(3.3)$ & $\begin{array}{l}\text { C08C Selective calcium channel blockers } \\
\text { with mainly vascular effects }\end{array}$ & $4(7.7)$ \\
\hline C09A ACE inhibitors, plain & $12(20)$ & C09A ACE inhibitors, plain & $14(26.9)$ \\
\hline \multirow[t]{2}{*}{ C09C Angiotensin II antagonists, plain } & $1(1.7)$ & C09C Angiotensin II antagonists, plain & $2(3.8)$ \\
\hline & & $\begin{array}{l}\text { C09D Angiotensin II antagonists, } \\
\text { combinations }\end{array}$ & $1(1.9)$ \\
\hline Antidiabetics & $10(16.7)$ & Antidiabetics & $6(11.5)$ \\
\hline A10B Oral blood glucose lowering drugs & $9(15)$ & A10B Oral blood glucose lowering drugs & $6(11.5)$ \\
\hline A10A Insulins and analogues & $1(1.7)$ & & \\
\hline $\begin{array}{l}\text { A02B Drugs for peptic ulcer and gastro- } \\
\text { oesophageal reflux disease (GORD) }\end{array}$ & $7(11.7)$ & $\begin{array}{l}\text { A02B Drugs for peptic ulcer and gastro- } \\
\text { oesophageal reflux disease (GORD) }\end{array}$ & $6(11.5)$ \\
\hline A12A Calcium & $5(8.3)$ & A12A Calcium & $3(5.8)$ \\
\hline B01A Antithrombotic agents & $9(15)$ & B01A Antithrombotic agents & $5(9.6)$ \\
\hline C10ALipid modifying agents, plain & $5(8.3)$ & C10ALipid modifying agents, plain & $3(5.8)$ \\
\hline H03A Thyroid preparations & $9(15)$ & H03A Thyroid preparations & $3(5.8)$ \\
\hline $\begin{array}{l}\text { M01A Anti-inflammatory and } \\
\text { antirheumatic products, non-steroids }\end{array}$ & $7(11.7)$ & $\begin{array}{l}\text { M01A Anti-inflammatory and } \\
\text { antirheumatic products, non-steroids }\end{array}$ & $5(9.6)$ \\
\hline N05B Anxiolytics & $10(16.7)$ & N05B Anxiolytics & $4(7.7)$ \\
\hline N06A Antidepressants & $8(13.3)$ & N06A Antidepressants & $9(17.3)$ \\
\hline
\end{tabular}

$\mathrm{n}=$ number of patients

$\dagger \mathrm{P}=0.02 ; \mathrm{OR}=0.48$ (95\% CI: $0.25-0.91)$.

There was no statistically significant difference between the percentage of medicated OLP patients $(54.5 \%)$ as compared with that of medicated control subjects (68.4\%) $(\mathrm{P}=0.08)$; nor was there any statistical difference between the percentage of medicated males and females of the OLP group $(\mathrm{P}=0.35)$ and of the control subjects $(\mathrm{P}=0.93)$.
The profile of drugs used among the 60 medicated OLP patients and the 52 medicated subjects of the control group is shown in (Table 2). The total number of different drugs was 65 in the medicated OLP patients and 67 in medicated subjects of the control group. The antihypertensives were the drugs most used by the medicated OLP patients (41.7\%) and by the medicated subjects of 
the control group $(55.8 \%)$, with the angiotensin-converting enzyme inhibitors being the most common antihypertensive drugs in both groups, used by $20 \%$ of the medicated OLP patients and $26.9 \%$ of the medicated control subjects. The anxiolytics (16.7\%), antidiabetics (16.7\%), thyroid preparations $(15 \%)$, antithrombotic agents (15\%), antidepressants (13.3\%), drugs for peptic ulcer and gastro-oesophageal reflux disease (11.7\%) and non-steroidal anti-inflammatories $(11.7 \%)$ comprised the other drugs most consumed by the medicated OLP patients, which, for the medicated subjects in the control group, were the antidepressants (17.3\%), antidiabetics (11.5\%), drugs for peptic ulcer and gastro-oesophageal reflux disease $(11.5 \%)$ antithrombotic agents $(9.6 \%)$, non-steroidal anti-inflammatories $(9.6 \%)$ and anxiolytics (7.7\%). In terms of the categories of drugs taken, the only statistically significant difference was that a higher percentage of control subjects were taking antihypertensives as compared to the OLP patients, $\mathrm{P}=0.02$; OR $=0.48$ (95\% CI: $0.25-0.91)$.

There was no statistically significant difference when the medicated OLP patients and medicated control sub- jects were compared in terms of monopharmacy, minor and major polypharmacy ( $\mathrm{P}>0.05$; (Table 3A). Daily use of topical oral medication was reported by only 2 $(1.8 \%)$ of the 110 OLP patients and by $1(1.3 \%) 76$ of the control group.

Thirty-nine $(65 \%)$ of the 60 medicated OLP patients and $37(71.1 \%)$ of the 52 medicated subjects in the control group were using drugs implicated in lichenoid reactions (DILRs), there being no statistically significant difference between these two groups in terms of using DILRs, regardless of the number of medications used daily $(\mathrm{P}>0.05$; (Table 3B).

The percentage of the clinical forms of OLP lesions in the patients using DILRs compared with the non-DILR and nonmedicated OLP patients are shown in (Table 4). The reticular and atrophic OLP lesions were the most prevalent forms in the two groups, with no statistically significant difference between them $(\mathrm{P}>0.05)$. The erosive form was seen less frequently in the patients using DILRs than in the non-DILR and nonmedicated patients, this difference being statistically significant $(\mathrm{P}<$ 0.05 ). The plaque form was only observed in 3 patients

Table 3. A) Classification of medicated OLP patients and medicated subjects of the control group according to the number of different drugs taken daily. B) Medicated OLP patients and medicated control subjects using drugs implicated in lichenoid reactions (DILRs). C) Nonmedicated OLP patients and control subjects.

\begin{tabular}{|c|c|c|c|c|c|c|}
\hline & \multicolumn{3}{|c|}{ OLP Group $(n=110)$} & \multicolumn{3}{|c|}{ Control Group $(n=76)$} \\
\hline & $\begin{array}{c}\text { Male (\%) } \\
\qquad \mathbf{N}=\mathbf{2 3}\end{array}$ & $\begin{array}{c}\text { Female }(\%) \\
\quad \mathbf{n}=\mathbf{8 7}\end{array}$ & $\begin{array}{c}\text { Total }(\%) \\
n=110\end{array}$ & $\begin{array}{c}\text { Male (\%) } \\
\qquad N=18\end{array}$ & $\begin{array}{c}\text { Female }(\%) \\
\qquad N=58\end{array}$ & $\begin{array}{c}\text { Total }(\%) \\
n=76\end{array}$ \\
\hline \multicolumn{7}{|l|}{$\begin{array}{l}\text { A) Medicated subjects } \\
\text { using any medication }\end{array}$} \\
\hline *Monopharmacy (\%) & $10(43.5)$ & $15(17.2)$ & $25(22.7)$ & $4(22.2)$ & $19(32.8)$ & $23(30.3)$ \\
\hline **Minor polypharmacy $(\%)$ & $2(8.7)$ & $26(29.9)$ & $28(32.2)$ & $4(22.2)$ & $17(29.3)$ & $21(27.6)$ \\
\hline$* * *$ Major polypharmacy $(\%)$ & $3(13)$ & $4(4.6)$ & $7(6.4)$ & $3(16.7)$ & $5(8.6)$ & $8(10.5)$ \\
\hline Total & $15(65.2)$ & $45(51.7)$ & $60(54.5)$ & $11(61.1)$ & $41(70.7)$ & $52(68.4)$ \\
\hline \multicolumn{7}{|l|}{$\begin{array}{l}\text { B) Medicated subjects } \\
\text { using DILRs }\end{array}$} \\
\hline$\dagger$ Monopharmacy (\%) & $4(17.3)$ & $15(17.2)$ & $19(17.2)$ & $9(50)$ & $11(19)$ & $20(26.3)$ \\
\hline$\dagger \uparrow$ Minor polypharmacy $(\%)$ & $2(8.6)$ & $18(20.6)$ & $20(18.2)$ & - & $17(29.3)$ & $17(22.3)$ \\
\hline Major polypharmacy (\%) & - & - & - & - & - & - \\
\hline Total & $6(26.0)$ & $33(37.9)$ & $39(35.4)$ & $9(50)$ & $28(48.3)$ & $37(48.6)$ \\
\hline C) Nonmedicated subjects & $8(34.8)$ & $42(48.3)$ & $50(45.5)$ & $7(38.9)$ & $17(29.3)$ & $24(31.6)$ \\
\hline
\end{tabular}

$\mathrm{n}=$ number of patients

DILRs $=$ drugs implicated in lichenoid reaction, based on Scully and Bagan (8)

$* \mathrm{P}=0.09$

$* * \mathrm{P}=0.24$

$* * * \mathrm{P}=0.13$

$\dagger \mathrm{P}=0.09$

$\dagger+\mathrm{P}=0.26$ 
Table 4. Comparison of the frequency of the clinical forms and distribution (uni/bilateral) of lesions in OLP patients using DILR with those of patients using non-DILR and no drugs.

\begin{tabular}{|l|c|c|c|}
\hline & $\begin{array}{c}\text { Patients using DILR } \\
(\mathbf{n = 3 9 )}\end{array}$ & $\begin{array}{c}\text { Patients using non-DILR } \\
(\mathbf{n = 2 1 )}\end{array}$ & $\begin{array}{c}\text { Nonmedicated subjects } \\
(\mathbf{n}=\mathbf{5 0})\end{array}$ \\
\hline Clinical forms of OLP & $36(92.3)$ & $18(85.7)$ & $46(92.0)$ \\
\hline Reticular (\%) & $19(48.7)$ & $10(47.6)$ & $27(54)$ \\
\hline Atrophic (\%) & $1(2.6)$ & $4(19.1) \dagger$ & $10(20) \dagger \dagger$ \\
\hline Erosive (\%) & $3(7.7)$ & $1(4.8)$ & $2(4.0)$ \\
\hline Plaque (\%) & & & $1(2.0)^{\mathbf{n s}}$ \\
\hline Uni / bilateral lesions of OLP & $2(5.1)$ & $1(4.8)^{\mathbf{n s}}$ & $49(98)$ \\
\hline Unilateral & $37(94.9)$ & $20(95.2)$ & \\
\hline Bilateral &
\end{tabular}

$\mathrm{n}=$ number of OLP patients

$\dagger$ Fisher's exact test, 2 tailed, $\mathrm{P}=0.04 ; \mathrm{OR}=0.11 ; 95 \% \mathrm{CI}(0.01-1.21)$

$\dagger \dagger$ Fisher's exact test, 2 tailed, $\mathrm{P}=0.02$; OR $=0.11 ; 95 \%$ CI $(0.01-0.87)$

ns $=$ Nonsignificant, Fisher's exact test, 2 tailed, $\mathrm{P}=1.0$

using DILRs and in 3 of the non-DILR/nonmedicated patients.

The buccal mucosa, tongue and gingiva were the sites most affected in patients using DILRs (100, 46.1, and $48.7 \%$, respectively) and in non-DILR/nonmedicated patients $(91.6,46.5$, and $43.7 \%$, respectively). The symptoms of oral discomfort, burning or pain were reported by $66.7 \%$ of those using DILR and in $67.6 \%$ of the nonDILR and nonmedicated patients, with no statistically significant difference between these two groups $(\mathrm{P}>$ $0.05)$.

Distribution of the lesions showed a predominant bilateral involvement of the lesions, occurring in $94.9 \%$ of OLP patients using DILRs and in $97.2 \%$ of the nonDILR/nonmedicated patients, with no significant statistical difference between these two groups $(\mathrm{P}>0.05$; (Table 4).

\section{Discussion}

The clinical profile of the OLP patients in this study shares many similarities with those reported by other authors, in terms of female predominance (female/male ratio 3.8:1), age of diagnosis (predominantly over 50 years) and the clinical pattern of the lesions (predominance of the reticular form with bilateral distribution) (4, 13-15).

The female predominance reported in the present study was even higher than those found in other studies $(4,10$, 14-16), in which the female/male ratio varied from 1.5:1 to $2.1: 1$. One possible explanation for this difference is that, routinely, more women $(64.5 \%)$ than men $(35.5 \%)$ come to our clinic for a diagnosis of some type oral mu- cosa lesion. In only 2 studies $(5,13)$, were the reported female/male ratio in OLP lesions (2.8: 1 and 3:1, respectively) fairly close to that observed in the present study. Although many drugs have been reported as potential inducers of LDRs $(5,8)$, the non-steroidal anti-inflammatory drugs (NSAIDs) and the antihypertensives, mostly the angiotensin-converting enzyme inhibitors (ACE inhibitors), are the drugs most frequently implicated in LDRs $(3,9,17)$. Two studies have shown a complete identification of NSAIDs as LDR inducers, with case history strongly suggesting a relationship between NSAID intake and the onset of OLP, with complete resolution or marked improvement of the lesions when these drugs were withdrawn as well as recurrence when patients were again given the offending drug $(9,10)$.

In the present study, the medicated OLP patients and medicated control-group subjects exhibited a similar profile in terms of daily medicine intake. However, this and another similar study (10) have shown that more control subjects were taking antihypertensives than OLP patients, with a statistically significant difference. These findings indicate that the antihypertensives do not likely act as LDR inducers, in fact it could be argued, pending further studies, that they are associated with a lower risk of OLP. A further controlled study (4), found no statistical difference between the percentage of subjects taking antihypertensives in the OLP and control groups. To date, the present study, along with (4) and (10) constitute the only 3 controlled studies in this regard.

In terms of the types of OLP lesions, the erosive form was found at a statistically significance greater frequen- 
cy in non-DILR and nonmedicated OLP patients than in patients taking DIRLs. This finding does not agree with a general tendency in the literature to associate the erosive form with DILR intake, but it is in agreement with the results of a large study involving 808 OLP patients (15), where the authors did not find a predominance of the erosive form in patients taking ACE inhibitors.

So, while there is no disagreement among authors that some drugs can cause LDR lesions, in light of the present study and others $(15,16)$, it seems that the prevalence of LDR lesions is low.

It is also generally agreed that OLP affects predominantly women, possibly suggesting a genetic predisposition to the development of OLP. This has given rise to the hypothesis that drug intake is correlated, in women, with an enhanced susceptibility to developing OLP lesions. However, only in one study have drug histories been found to be significantly more prevalent in female patients with OLP as compared to males (4). Other studies, in agreement with the present study, have found that the medical status of female patients with OLP did not differ significantly from that of males $(10,18)$.

OLP is considered a cell-mediated immunological disease, but what elicits the immune response is uknown. Likewise, the role of drugs in the etiology of LDRs is poorly understood and most likely complex. It seems clear, however, that a majority of OLP cases are not directly linked to the use of systemic medication, which is in accordance with the findings of a previous study (16). Diagnosis of LDR lesions can only be made by verifying that remission occurs upon withdrawal of medication coupled with recurrence on re-challenge. In cases of LDRs where the regime of medication cannot be substituted, reduced or withdrawn, symptomatic patients can be treated with topical medication, mostly by application of corticosteroids $(19,20)$.

\section{References}

References with links to Crossref - DOI

1. Sugerman PB, Savage NW, Walsh LJ, Zhao ZZ, Zhou XJ, Khan A, et al. The pathogenesis of oral lichen planus. Crit Rev Oral Biol Med. 2002;13:350-65.

2. Lodi G, Scully C, Carrozzo M, Griffiths M, Sugerman PB, Thongprasom K. Current controversies in oral lichen planus: report of an international consensus meeting. Part 1. Viral infections and etiopathogenesis. Oral Surg Oral Med Oral Pathol Oral Radiol Endod. 2005;100:40-51.

3. Scully C, Beyli M, Ferreiro MC, Ficarra G, Gill Y, Griffiths M, et al. Update on oral lichen planus: etiopathogenesis and management. Crit Rev Oral Biol Med. 1998;9:86-122.

4. Kragelund C, Thomsen CE, Bardow A, Pedersen AM, Nauntofte $\mathrm{B}$, Reibel J, et al. Oral lichen planus and intake of drugs metabolized by polymorphic cytochrome P450 enzymes. Oral Dis. 2003;9:17787.

5. Lamey PJ, McCartan BE, MacDonald DG, MacKie RM. Basal cell cytoplasmic autoantibodies in oral lichenoid reactions. Oral Surg Oral Med Oral Pathol Oral Radiol Endod. 1995;79:44-9.

6. McCartan BE, McCreary CE. Oral lichenoid drug eruptions. Oral Dis. 1997;3:58-63.

7. Halevy S, Shai A. Lichenoid drug eruptions. J Am Acad Dermatol. 1993;29:249-55.
8. Scully C, Bagan JV. Adverse drug reactions in the orofacial region. Crit Rev Oral Biol Med. 2004;15:221-39.

9. Hamburger J, Potts AJ. Non-steroidal anti-inflammatory drugs and oral lichenoid reactions. Br Med J (Clin Res Ed). 1983;287:1258.

10. Potts AJ, Hamburger J, Scully C. The medication of patients with oral lichen planus and the association of nonsteroidal anti-inflammatory drugs with erosive lesions. Oral Surg Oral Med Oral Pathol. 1987;64:541-3

11. Kramer IR, Lucas RB, Pindborg JJ, Sobin LH. Definition of leukoplakia and related lesions: an aid to studies on oral precancer. Oral Surg Oral Med Oral Pathol. 1978;46:518-39.

12. World Health Organization [Internet]. Oslo (Norway): ATC/DDD Index 2010; [update 2009 Oct 27; cited 2009 Dec. 5]. WHO Collaborating Centre for Drug Statistics Methodology, Norwegian Institute of Public Health. Available from: http://www.whocc.no/atcddd.

13. Eisen D. The clinical features, malignant potential, and systemic associations of oral lichen planus: a study of 723 patients. J Am Acad Dermatol. 2002;46:207-14.

14. Xue JL, Fan MW, Wang SZ, Chen XM, Li Y, Wang L. A clinical study of 674 patients with oral lichen planus in China. J Oral Pathol Med. 2005;34:467-72.

15. Carbone M, Arduino PG, Carrozzo M, Gandolfo S, Argiolas MR, Bertolusso G, et al. Course of oral lichen planus: a retrospective study of 808 northern Italian patients. Oral Dis. 2009;15:235-43.

16. Thorn JJ, Holmstrup P, Rindum J, Pindborg JJ. Course of various clinical forms of oral lichen planus. A prospective follow-up study of 611 patients. J Oral Pathol. 1988;17:213-8.

17. Eisen D, Carrozzo M, Bagan Sebastian JV, Thongprasom K. Number V Oral lichen planus: clinical features and management. Oral Dis. 2005;11:338-49.

18. Ingafou M, Leao JC, Porter SR, Scully C. Oral lichen planus: a retrospective study of 690 British patients. Oral Dis. 2006;12:463-8. 19. Lodi G, Scully C, Carrozzo M, Griffiths M, Sugerman PB, Thongprasom K. Current controversies in oral lichen planus: report of an international consensus meeting. Part 2. Clinical management and malignant transformation. Oral Surg Oral Med Oral Pathol Oral Radiol Endod. 2005;100:164-78.

20. Van der Waal I. Oral lichen planus and oral lichenoid lesions; a critical appraisal with emphasis on the diagnostic aspects. Med Oral Patol Oral Cir Bucal. 2009;14:E310-4. 